\title{
MEN1-associated primary hyperparathyroidism in the Spanish Registry: clinical characterictics and surgical outcomes
}

\author{
Cristina Lamas ${ }^{1}$, Elena Navarro², Anna Casterás ${ }^{3}$, Paloma Portillo $^{4}$, Victoria Alcázar ${ }^{5}$, María Calatayud ${ }^{6}$, \\ Cristina Álvarez-Escolá7, Julia Sastre ${ }^{8}$, Evangelina Boix ${ }^{9}$, Lluis Forga ${ }^{10}$, Almudena Vicente ${ }^{8}$, Josep Oriola ${ }^{11}$, \\ Jordi Mesa ${ }^{3}$ and Nuria Valdés ${ }^{12}$ \\ ${ }^{1}$ Department of Endocrinology and Nutrition, Complejo Hospitalario Universitario de Albacete, Albacete, Spain \\ ${ }^{2}$ Department of Endocrinology and Nutrition, Hospital Universitario Virgen del Rocío, Sevilla, Spain \\ ${ }^{3}$ Department of Endocrinology and Nutrition, Hospital Vall d'Hebron, Barcelona, Spain \\ ${ }^{4}$ Department of Endocrinology and Nutrition, Hospital Clínico Universitario Virgen de la Arrixaca, Murcia, Spain \\ ${ }^{5}$ Department of Endocrinology and Nutrition, Hospital Universitario Severo Ochoa, Leganés, Spain \\ ${ }^{6}$ Department of Endocrinology and Nutrition, Hospital Univeristario Doce de Octubre, Madrid, Spain \\ ${ }^{7}$ Department of Endocrinology and Nutrition, Hospital Universitario La Paz, Madrid, Spain \\ ${ }^{8}$ Department of Endocrinology and Nutrition, Complejo Hospitalario de Toledo, Hospital Virgen de la Salud, Toledo, Spain \\ ${ }^{9}$ Department of Endocrinology and Nutrition, Hospital General Universitario de Elche, Elche, Spain \\ ${ }^{10}$ Department of Endocrinology and Nutrition, Complejo Hospitalario de Navarra, Hospital de Navarra, Pamplona, Spain \\ ${ }^{11}$ Biochemistry and Molecular Genetics Department, Hospital Clínic i Universitari de Barcelona, Barcelona, Spain \\ ${ }^{12}$ Department of Endocrinology and Nutrition, Hospital Universitario Central de Asturias, Oviedo, Spain
}

Correspondence should be addressed to C Lamas: clamaso@sescam.jccm.es

\begin{abstract}
Primary hyperparathyroidism is the most frequent manifestation of multiple endocrine neoplasia type 1 (MEN1) syndrome. Bone and renal complications are common. Surgery is the treatment of choice, but the best timing for surgery is controversial and predictors of persistence and recurrence are not well known. Our study describes the clinical characteristics and the surgical outcomes, after surgery and in the long term, of the patients with MEN1 and primary hyperparathyroidism included in the Spanish Registry of Multiple Endocrine Neoplasia, Pheochromocytomas and Paragangliomas (REGMEN). Eighty-nine patients (49 men and 40 women, $34.2 \pm 13$ years old) were included. Sixtyfour out of the 89 underwent surgery: a total parathyroidectomy was done in 13 patients, a subtotal parathyroidectomy in 34 and a less than subtotal parathyroidectomy in 15 . Remission rates were higher after a total or a subtotal parathyroidectomy than after a less than subtotal ( $3 / 4$ and $20 / 22$ vs $7 / 12, P<0.05$ ), without significant differences in permanent hypoparathyroidism (1/5, 9/23 and 0/11, N.S.). After a median follow-up of 111 months, 20 of the 41 operated patients with long-term follow-up had persistent or recurrent hyperparathyroidism. We did not find differences in disease-free survival rates between different techniques, patients with or without permanent hypoparathyroidism and patients with different mutated exons, but a second surgery was more frequent after a less than subtotal parathyroidectomy.
\end{abstract}

\section{Introduction}

Multiple endocrine neoplasia type 1 (MEN1) syndrome is a rare hereditary disease, with an estimated prevalence of $0.15-0.30$ cases per 1000 in general population $(1,2)$. Primary hyperparathyroidism (PHPT) is its most common manifestation: most carriers of a MEN1 mutation will have developed PHPT by age 50 years. It is also the first https://ec.bioscientifica.com https://doi.org/10.1530/EC-19-0321 (c) 2019 The authors Published by Bioscientifica Ltd

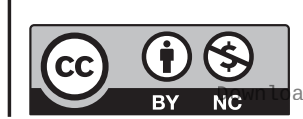

This work is licensed under a Creative Commons Attribution-NonCommercial 4.0 International License. ded from Bioscientifica.com at 04/26/2023 10:10:24AM
Endocrine Connections (2019) 8, 1416-1424 
clinical manifestation, usually diagnosed before 30 years of age, and bone and renal complications are common. However, not many clinical studies about this specific type of PHPT have been published in recent years. Total parathyroidectomy (TPTX) with autotransplantation of parathyroid tissue in a forearm muscle or subtotal parathyroidectomy (SPTX) is the treatment of choice. A simultaneous transcervical thymectomy is also recommended, to remove a putative intrathymic parathyroid gland and to prevent the development of a subsequent thymic carcinoid tumor. Controversies persist regarding the role of presurgical localization studies or the ideal timing for surgery, both at initial diagnosis and at recurrence. Hyperplasia affecting all the parathyroid tissue is the most common pathological finding, making recurrences much more frequent than in sporadic hyperparathyroidism, so PHPT often represents an active disease for many years in a patient's lifespan $(1,2,3,4,5)$.

The aim of this study was to describe the clinical characteristics, diagnostic studies, treatment and follow-up of all the patients with MEN1 and PHPT included in the REGMEN (the Spanish Registry of Multiple Endocrine Neoplasia, Pheochromocytmas and Paragangliomas (PPGL)).

\section{Patients and methods}

The REGMEN is a collaborative and multicentric project designed by the Spanish Group for the Study of MEN and PPGL. The registry is an online database designed to collect extensive clinical information about patients with MEN1, MEN2A, MEN2B, and PPGL, both prospectively and retrospectively. It has been approved by the Ethical Committee of the Principado de Asturias. Informed consent was obtained from all patients prior to their inclusion in the registry.

Demographics, symptoms at diagnosis, biochemical and densitometric parameters and imaging studies were obtained from the medical records, as well as treatments and their results.

The diagnosis of PHPT was made in the presence of hypercalcemia and non-suppressed PTH or normocalcemic hyperparathyroidism (high PTH, normocalcemia, excluding other causes for secondary hyperparathyroidism). Bone mineral density (BMD) was assessed using dual-energy X-ray absorptiometry. Osteoporosis was established when the $\mathrm{T}$ score at any studied bone site was under -2.5 , and osteopenia when $\mathrm{T}$ score was under -1 (6). Z score was not analyzed since it had been registered in a very small number of cases.
Patients were considered to have a TPTX if all identified parathyroid glands were removed, usually with autotransplantation of parathyroid tissue into the nondominant forearm or the neck, and a SPTX if three or more parathyroid glands were removed, leaving one or a partial gland behind. Any lesser resection was considered less than SPTX (<SPTX). Criteria for persistency and recurrence were the same as for initial diagnosis. A recurrence was diagnosed when PHPT recurred after at least 6 months of normal calcium and PTH. Permanent hypoparathyroidism was defined as lasting for more than 6 months.

\section{Statistical analysis}

For the analysis, categorical variables were summarized as frequency counts and percentages. Continuous variables were summarized as the mean +standard deviation when normal and as the median and range or interquartile range (IR) when not normal, unless otherwise specified. The normal distribution of the quantitative variables was verified or excluded using the Kolmogorov-Smirnov test for normality. Some parameters analyzed in different time points followed the normal distribution at some points, but not at others, and are therefore presented as median and range or IR. Chi-square and Fisher's exact test in case of categorical variables and Student $t$-test or Mann-Whitney $U$ test for quantitative variables were used for comparisons. The relation between categorical variables (surgical technique, presence or absence of hypoparathryroidism and mutated exon) and persistent/ recurrent PHPT was analyzed using Kaplan-Meier survival analysis and the log-rank test. To evaluate changes in medical practices or results over time, patients were grouped together by their decade of diagnosis. IBM SPSS Statistics, version 22 was used for data analysis.

\section{Results}

\section{Baseline patients' characteristics}

Among the 112 patients with MEN1 mutation from 39 different families registered in REGMEN, 94 had been diagnosed with PHPT. Five patients were excluded due to significant missing information. The remaining 89 patients were included in the analysis. They were 49 men and 40 women with a mean age at diagnosis of PHPT of $34.2 \pm 13$ years and had been diagnosed between 1979 and 2015 in 17 Spanish hospitals. Twenty-one of them

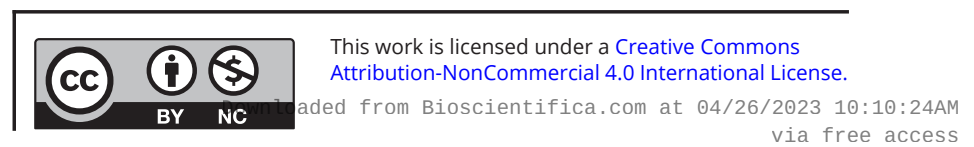


were the index case in their family, while 34 had been diagnosed through biochemical screening and 27 through genetic screening; information about the other seven was missing. Higher prevalence of genetic screening in more recent years was not observed. Genetic testing had been done in 87 patients and a mutation had been found in all but four of them. Exon 10 was the most commonly affected (45 cases), but a single family was responsible for 20 of the 45 cases; exon 3 (11 patients), exon 2 (9 patients) and exon 7 (5 patients) were also commonly affected, but mutations in exons 4, 5, 6 and 9 were also found. Four members of one family had impaired splicing due to an intronic mutation.

Fifty patients were asymptomatic at diagnosis, 29 patients had developed kidney stones, gastrointestinal symptoms were present in eight patients, bone symptoms in three and neuromuscular symptoms in one. Age at diagnosis and sex were similar between symptomatic and asymptomatic patients $(32.6 \pm 13.6$ vs $36.5 \pm 12$, N.S.; 30/50 women vs 19/39, N.S.). Symptoms were more frequent in index cases than in patients diagnosed through biochemical or genetic screening (19/27 vs 12/34 and $8 / 27$ respectively, $P=0.026$ ), even if the age was similar in the three groups.

Biochemical parameters at diagnosis are summarized in Table 1. Serum PTH levels were moderately associated with serum calcium levels $(r=0.42, P=0.002)$. PTH, but not calcium, correlated with age $(r=0.40, P=0.002)$. Patients with nephrolithiasis had higher PTH (median 15.3 , IR $11.8-19.9$ vs 8.9 , IR $6.8-12.2 \mathrm{pmol} / \mathrm{L}, P=0.001$ ), but age and calcium were not different from patients without nephrolithiasis. Renal function was normal in every patient.
BMD was measured before surgery in thirty-three patients, that were not older than the whole cohort nor were diagnosed more recently, and it was classified as osteopenia in 8 and as osteoporosis in 11, without differences between men and women. Patients with osteoporosis were significantly older than those with osteopenia or normal bone mass $(42.8 \pm 18.3$ vs $36.4 \pm 9$ and $28 \pm 10$ years respectively, $P=0.028)$. No correlation was found between calcium and PTH levels and bone mass, even if there was a non-significant trend to higher PTH values in those with worse bone mass (9, 10.1 and $14.1 \mathrm{pmol} / \mathrm{L}$ in normal bone mass, osteopenia and osteoporosis respectively). Only two bone fractures were registered at presentation: a vertebral fracture in a 25-year-old man and a distal radius fracture in a 50-yearold woman.

Forty-eight had at least one localization study and thirty-three had at least two (Table 1).

\section{Surgical treatment}

Sixty-four patients had undergone parathyroid surgery. Presurgical biochemical parameters are summarized in Table 2. Surgery was recommended because of the patient's age in 39 patients, due to renal involvement in 22 patients, due to symptomatic hyperparathyroidism in 10 patients, due to bone involvement in 10 patients and because of the degree of hypercalcemia in 2 patients: more than one reason were registered in several patients.

The first surgical intervention took place between 1981 and 2014, in the first year after the diagnosis of PHPT in 39 patients and after a median of 26 months in the other 25 (range 13-265 months). Patients with delayed

Table 1 Clinical, biochemical and densitometric parameters and localization studies at diagnosis. Frequency counts, mean and standard deviation or median and range are presented. Densitometric parameters were available for 33 patients. The number of patients that underwent each localization technique, as well as the number that were positive are presented.

\section{Parameter}

Women/men

Age at diagnosis (years)

Serum calcium ( $\mathrm{mmol} / \mathrm{L})$

PTH (pmol/L)

24-h urine calcium (mmol/24 h)

Creatinine ( $\mu \mathrm{mol} / \mathrm{L})$

Lumbar spine T score

Femoral neck T score

Normal bone mass/osteopenia/osteoporosis

Scintigraphy

Ultrasonography

SPECT-CT

Computed tomography

Magnetic resonance imaging

Value
$40 / 49$
$34.2 \pm 13$
$2.75(2.64-2.89)$
$9.8(7.6-15.1)$
$8.78(6.08-10.48)$
$70.7(58.3-79.6)$
$-0.04(-1.62$ to 0.51$)$
$0.06(-1.96$ to 0.56$)$

$14 / 8 / 11$ https://ec.bioscientifica.com

https://doi.org/10.1530/EC-19-0321 (c) 2019 The authors Published by Bioscientifica Ltd
45

30

6

4

6
34 positive

16 positive

5 positive

2 positive

5 positive 
Table 2 Presurgical clinical data (or data at diagnosis for non-operated patients) and surgical outcomes in patients undergoing surgery with different techniques. The data from the two patients with no information about the surgical technique are not included. Data are presented as mean (age), median (all other quantitative parameters) or as frequency counts of available data (persistence, hypoparathyroidism, recurrence and reoperations). Follow-up is considered from surgery to the last follow-up visit in operated patients and from diagnosis in non-operated patients. Only patients with long-term follow-up are considered for recurrence and permanent hypoparathyroidism analysis.

\begin{tabular}{|c|c|c|c|c|c|}
\hline & No surgery & $<$ SPTX & SPTX & TPTX & Total \\
\hline No. of patients & 25 & 15 & 34 & 13 & 89 \\
\hline Men/women & $9 / 16$ & $9 / 6$ & $14 / 20$ & $7 / 6$ & $49 / 40$ \\
\hline Age at diagnosis & 34.3 & 35.2 & 32.2 & 38.2 & 34.3 \\
\hline Age at 1 st surgery & - & 35.9 & 34.4 & 38.1 & 35.5 \\
\hline Presurg calcium (mmol/L) & 2.69 & 2.75 & 2.84 & 2.50 & 2.75 \\
\hline Presurg PTH (pmol/L) & 8.2 & 12.5 & 9.8 & 6.9 & 9.8 \\
\hline Follow-up (months) & 146 & 108 & 84 & 204 & 116 \\
\hline Persistence & - & $5 / 12^{a}$ & $2 / 22$ & $1 / 4$ & $8 / 38$ \\
\hline Hypoparat & - & $0 / 11$ & $9 / 23$ & $1 / 5$ & $10 / 39$ \\
\hline Persistence + recurrence & - & $7 / 11$ & $12 / 23$ & $1 / 6$ & $20 / 41$ \\
\hline Reoperation & - & $4 / 11$ & $3 / 23$ & $0 / 6$ & $6 / 41$ \\
\hline
\end{tabular}

hypoparat, permanent hypoparathyroidism; presurg, presurgical; <SPTX, less than subtotal parathyroidectomy; SPTX, subtotal parathyroidectomy; TPTX, total parathyroidectomy.

a $P<0.05$ when compared to SPTX and TPTX.

surgery had lower calcium and PTH levels at diagnosis $(2.72 \pm 0.12$ vs $2.97 \pm 0.3 \mathrm{mmol} / \mathrm{L}, P=0.026$, and $10.4 \pm 3.6$ vs $20.4 \pm 20.5 \mathrm{pmol} / \mathrm{L}, P=0.028)$, but they raised over time and presurgical values were not different between patients with early and delayed surgery. Patients with delayed surgery were less symptomatic at diagnosis ( $8 / 25$ vs $25 / 39$, $P=0.012$ ), but no differences were found in calcium urinary excretion or renal function, age, sex, type of diagnosis, BMD, surgical technique or surgical outcome. Nephrolithiasis was less prevalent (6/25 vs $18 / 39)$, but the difference did not reach statistical significance $(P=0.07)$.

A SPTX was the most common procedure (thirtyfour patients), with autotransplantation in five of them.

Table 3 Surgical techniques throughout the decades covered by the study: the differences were not statistically significant.

\begin{tabular}{|c|c|c|}
\hline Decade & Number of patients & Surgical technique \\
\hline 1980-1989 & 11 & $\begin{array}{l}1 \text { unknown } \\
1 \text { <SPTX } \\
8 \text { SPTX } \\
1 \text { TPTX }\end{array}$ \\
\hline 1990-1999 & 11 & $\begin{array}{l}2<\text { SPTX } \\
4 \text { SPTX } \\
5 \text { TPTX }\end{array}$ \\
\hline 2000-2009 & 26 & $\begin{array}{l}1 \text { unknown } \\
8<\text { SPTX } \\
13 \text { SPTX } \\
4 \text { TPTX }\end{array}$ \\
\hline 2010-2015 & 16 & $\begin{array}{l}4 \text { <SPTX } \\
9 \text { SPTX } \\
3 \text { TPTX }\end{array}$ \\
\hline
\end{tabular}

<SPTX, less than subtotal parathyroidectomy; SPTX, subtotal parathyroidectomy; TPTX, total parathyroidectomy.
A TPTX was done in 13 patients, with autotransplantation in 10. No information about the surgical technique was available for two patients. The remainder 15 patients had a $<$ SPTX. A transcervical thymectomy was performed in 19 patients. Surgical technique did not correlate with the results of localization studies nor with the decade of surgery (Table 3). An ectopic parathyroid gland was described in two patients.

Parathyroid hyperplasia was described by the pathologist in 47 cases, one or more parathyroid adenomas in 19 cases, and normal parathyroid glands in 10. Eleven patients had more than one pathological diagnosis. Pathological reports were missing for five patients.

Postsurgical evaluation was available in 38 patients: eight of them had persistent hyperparathyroidism and ten permanent hypoparathyroidism (Table 2). TPTX and SPTX were equally effective achieving remission, and both were superior to $<$ SPTX $(P=0.009)$. No significant difference was found in hypoparathyroidism rates, even though no cases were diagnosed in the patients with $<$ SPTX. Age at diagnosis, sex, presurgical calcium and PTH levels, thymectomy, and histology were not significant prognostic factors for remission. Surgical outcome in relation to mutated exon is presented in Table 4 .

\section{Long-term follow-up}

Long-term postsurgical follow-up was available for 41 patients. After a median follow-up of 111 months, persistent or recurrent PHPT was found in 20 patients:

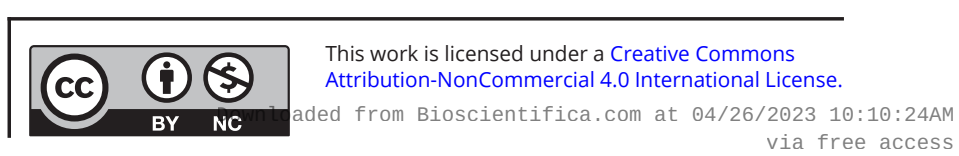


Table 4 Surgical outcomes in the 57 operated patients harboring mutations in different exons of the MEN1 gene $(P<0.001$ for chi-square test analysis of the whole table; paired comparisons were not done due to the small number of cases in each category). Genetic study revealed an intronic mutation in four members of the same family, no mutation was found in two patients and no genetic study was available for one more patient.

\begin{tabular}{lccccc}
\hline & Exon 2 & & Exon 3 & Exon 4 \\
\cline { 1 - 1 } \cline { 5 - 6 } \cline { 5 - 6 } Persistence & 4 & & 0 & 1 \\
Remission & 2 & & 3 & 0 \\
Unknown & 2 & & 3 & 0 \\
\hline
\end{tabular}

7/11 after <SPTX, 12/23 after SPTX and 1/6 after TPTX. A patient with unknown surgical technique did not recur. Kaplan-Meier estimates of disease-free survival did not reveal differences among surgical techniques (Fig. 1A), between patients with and without permanent hypoparathyroidism (Fig. 1B) or patients with different mutated exons (data not shown). However, when analyzing the probability of having a second surgery, the risk was higher in patients with a $<$ SPTX at their first surgery (Fig. 2).

Seventeen patients had a second surgery 92 months (median) after the first one (range 9-251; 78.5 after $<$ SPTX, 105 after SPTX and 91.8 after TPX, N.S.): six because of persistent hypercalcemia and six recurrences (two of them after a long time in hypoparathyroidism); no clinical information between surgeries was available for five patients. Severe hypercalcemia was not found in any patient. Eight of them had had a SPTX, six a $<$ SPTX, two a TPTX, and the surgical technique was missing in one. Autotransplantation was decided for six patients. A transcervical thymectomy was done in 7 of the 15 patients without it. Postsurgical evaluation was available for 12 of the 17 patients: hyperparathyroidism persisted in 3, and permanent hypoparathyroidism developed in 5 patients (5/12 vs 10/39 in the first intervention, N.S.). Two patients had a third surgery because of persistent hypercalcemia: one was a failed exploration of

\begin{tabular}{c}
\hline Exon $\mathbf{5}$ \\
\hline 0 \\
0 \\
1 \\
\hline
\end{tabular}

\begin{tabular}{c}
\hline Exon 6 \\
\hline 0 \\
3 \\
1 \\
\hline
\end{tabular}

\begin{tabular}{c}
\hline Exon 7 \\
\hline 0 \\
4 \\
0 \\
\hline
\end{tabular}

\begin{tabular}{|c|c|}
\hline Exon 9 & Exon 10 \\
\hline 0 & 3 \\
\hline 0 & 15 \\
\hline 3 & 12 \\
\hline
\end{tabular}

the arm implant and the other a successful total thyroidectomy.

No follow-up after diagnosis was available for 11 patients. In the last follow-up visit, 14 patients with PHPT had not been operated, after a median follow-up since diagnosis of 147 months (47-302). They were $43.4 \pm 18.5$ years old, median serum calcium was $2.69 \mathrm{mmol} / \mathrm{L}$ (2.42-3.24) and serum PTH was 9.9 pmol/L (4-30.5). The 41 operated patients with follow-up (median 111 months, range 2-392) were $48.9 \pm 12$ years old at their last visit, their serum calcium was $2.45 \mathrm{mmol} / \mathrm{L}(1.4-2.77)$ and their PTH 7.2 pmol/L (0.3-16.2). Five patients suffered permanent hypoparathyroidism. Seven patients died during follow-up (Table 5).

\section{Discussion}

Clinical registries of rare diseases allow to collect information from a high number of patients gathering data from different hospitals in real practice. The aim of our project is to improve our knowledge about this disease, its manifestations in the long term, our current clinical practice and the outcomes of surgery. The multicentric participation in the registry allows a generalization of our findings to the real situation of MEN1 patients in our country: even if most participating centers were
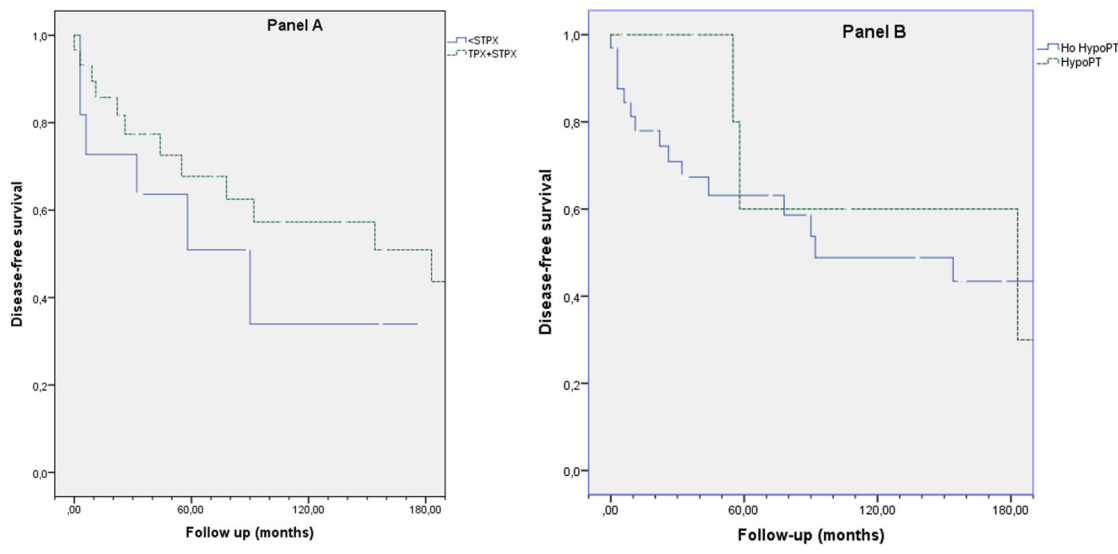

Figure 1

Kaplan-Meier estimates of disease-free survival after surgery for PHPT in MEN1 patients. Follow-up is displayed in months. No significant differences were found when comparing different surgical techniques (A) or patients with or without permanent hypoparathryroidism (B).

https://ec.bioscientifica.com https://doi.org/10.1530/EC-19-0321 (c) 2019 The authors Published by Bioscientifica Ltd

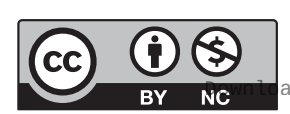

This work is licensed under a Creative Commons Attribution-NonCommercial 4.0 International License. ded from Bioscientifica.com at 04/26/2023 10:10:24AM via free access 


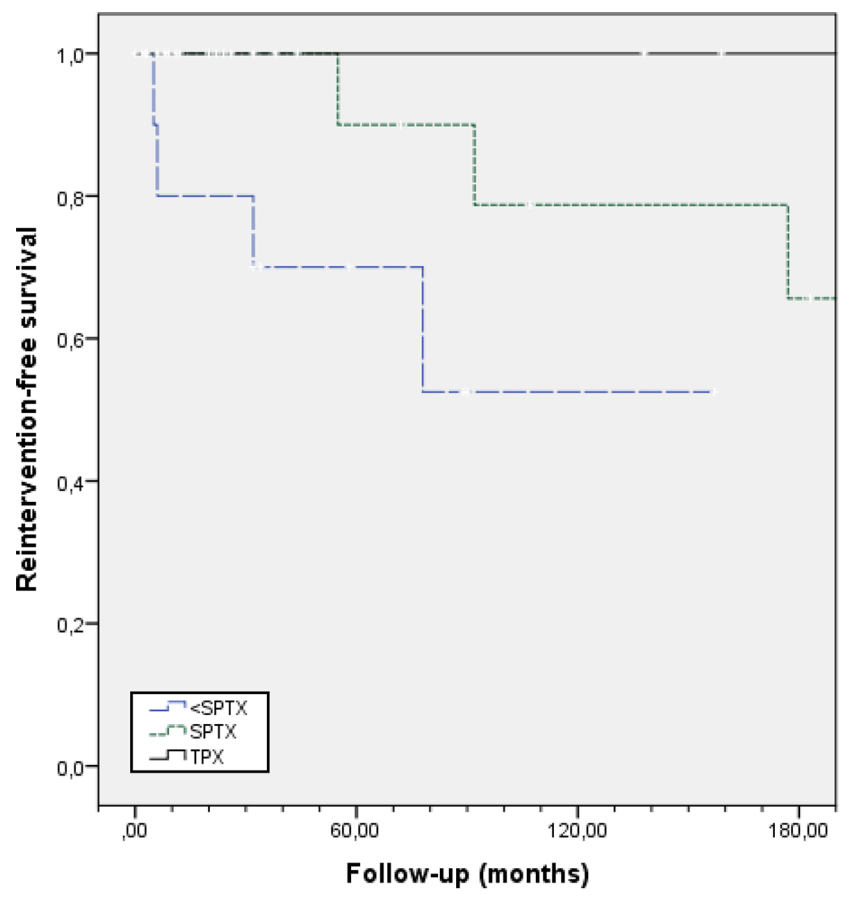

Figure 2

Kaplan-Meier estimates of reintervention-free survival after surgery for PHPT in MEN1 patients. Follow-up is displayed in months. The risk for a second surgery is higher for patients who had a less than subtotal parathyroidectomy $(\angle \mathrm{SPTX})$ at their first surgery $(P=0.034)$.

university tertiary hospitals, those are where most MEN1 patients are cared for. An inclusion bias is unlikely since most participating centers have included all their MEN1 patients.

Our series is similar to others in the equal incidence in both sexes and a mean age at diagnosis in the thirties $(7,8,9,10,11)$. However, a significant number (15) of patients were diagnosed over the age of 50 years, most of them as parents of an index case, or less commonly after a parathyroidectomy for a suspected sporadic PHPT. Unlike other series (12), index patients were not older than patients diagnosed through biochemical or genetic screening.

Clinical presentation was often mild or asymptomatic, with mild elevations of serum calcium and PTH in

Table 5 Causes of death during follow-up and time to death occurrence from diagnosis (months).

\begin{tabular}{|c|c|c|}
\hline Cause of death & $\begin{array}{c}\text { Number of } \\
\text { patients }\end{array}$ & $\begin{array}{c}\text { Months after } \\
\text { diagnosis }\end{array}$ \\
\hline Surgical complication & 1 & 10 \\
\hline Gastroenteropancreatic tumor & 3 & $40-177-208$ \\
\hline Adrenocortical carcinoma & 1 & 205 \\
\hline Metastatic adenocarcinoma & 1 & 62 \\
\hline Acute pancreatitis & 1 & 55 \\
\hline $\begin{array}{l}\text { https://ec.bioscientifica.com } \\
\text { https://doi.org/10.1530/EC-19-0321 }\end{array}$ & Publi & $\begin{array}{l}\text { (c) } 2019 \text { The autho } \\
\text { d by Bioscientifica L }\end{array}$ \\
\hline
\end{tabular}

all the patients both at diagnosis and at recurrences, but nephrolithiasis had been diagnosed in 32.6\%, and osteoporosis in 33\% of those undergoing a bone densitometry. The prevalence of nephrolithiasis is lower compared to other series $(13,14)$, probably because we registered its prevalence at diagnosis and others have registered the prevalence in their whole MEN1 population. Prevalence of bone loss has been studied in heterogeneous groups in relation to age and PHPT duration and using very different criteria ( $\mathrm{T}$ score lower than -2 or $-2.5, \mathrm{Z}$ score lower than -2 ), leading to a wide variability in low bone mass rates, from 17 to $47 \%(14,15,16,17)$ : our results do not differ significantly from those figures. As expected, osteoporosis risk increased with aging. Serum calcium did not correlate with the severity of clinical presentation, but serum PTH was higher in patients with nephrolithiasis and there was also a non-significant trend to higher PTH values in those with worse bone mass.

Presurgical localization studies were done in more than half of our patients, even if they are not recommended in MEN1 syndrome for deciding about the surgical technique $(2,18,19)$, and they seldom identify all parathyroid tissue, including supernumerary glands. As a matter of fact, many patients underwent SPTX or TPTX independently of the imaging findings. However, their utilization may be justified as a useful tool for the presurgical identification of ectopic or supernumerary glands before reintervention.

Sixty-four out of our 89 patients had at least one parathyroidectomy, a similar proportion compared to the French and Belgian MEN1 registry (7). Information about surgery indication rates in other countries is scarce since many studies include only operated patients. Since the best timing for parathyroid surgery in MEN1 remains unknown $(1,2,18)$, more studies are needed analyzing long-term development of complications in treated and untreated patients, or comparing patients with early versus delayed surgery. Early surgery may prevent bone and renal damage, but parathyroid identification at surgery is more difficult due to smaller size (18). It may also entail a higher probability of needing a second surgery through the lifespan, since recurrence rates increase in relation to the follow-up time: reintervention is more challenging because of postoperative fibrosis, leading to worse results and a higher risk of complications. Our contribution in this area is limited: some patients were operated on just after diagnosis, while others had surgery many years after. We could only identify the presence of symptoms and higher levels of calcium and PTH as factors leading to earlier surgery, so probably much of this variability in 
clinical practice is due to different criteria of the treating physicians, in the absence of evidence-based guidelines. Some non-operated patients had stable calcium levels in the high-normal range for many years and did not develop complications, but the small number of cases hinders any solid conclusion. Longitudinal studies are still needed to establish the best timing for parathyroidectomy.

Current guidelines agree that parathyroid surgery is the elective treatment for PHPT in patients with MEN1 and that SPTX, leaving a viable 30- to 50-mg remnant from the most normal-appearing gland, or TPTX with autotransplantation, in combination with transcervical thymectomy, are the procedures of choice $(2,4,5,7,10$, $11,19)$. Parathyroid surgery in the context of MEN1 is more challenging compared to sporadic PHPT, due to higher risk of persistent and recurrent disease and higher complications rates. Our results support these statements: postsurgical remission rates were significantly higher with SPTX or TPTX than with $<$ SPTX. However, at least four patients in the <SPTX were index cases and underwent surgery before the diagnosis of MEN1, with persistence of hypercalcemia in three of them and recurrence after initial remission in the other one: three of them had a second surgery. Surgical prognosis is undoubtedly worse in this situation, and efforts should be made to avoid a delay of the diagnosis of MEN1 in young patients with PHPT. The lower rate of hypoparathyroidism after <SPTX did not reach statistical significance, probably due to the small number of patients in each category. We could not statistically prove the differences in recurrence-free survival after different surgical techniques, in contrast with other studies $(8,10,11,20,21)$; the reduced percentage (64\%) of operated patients with complete follow-up data may have contributed to this unexpected negative result. However, the risk for a second surgery was higher after $<$ SPTX, suggesting a more severe disease at recurrence in this group or a higher predisposition for reintervention among physicians when they know that an incomplete surgery has been done in the first attempt. Postsurgical hypoparathyroidism was not associated with a lower risk of recurrence, as opposed to the results of another series (11). In recent years unilateral clearance, a specific form of minimally invasive parathyroidectomy, has been proposed $(22,23)$ : patients with a single abnormal parathyroid gland in presurgical imaging studies undergo excision of the abnormal gland, followed by excising the ipsilateral gland as well as the ipsilateral cervical thymus. In case of recurrence, a second surgery can be confined to the contralateral neck, a virgin operative field, preventing fibrosis and therefore minimizing the probability of recurrent laryngeal nerve damage and other surgical complications. Two small cohorts of six and eight patients respectively have shown remission rates comparable to standard surgery with lower rates of hypoparathyroidism $(22,23)$, but larger series and longer follow-up are needed. We cannot contribute to evaluate this technique since it was not the standard practice in our country in the years covered by the registry.

Age at PHPT diagnosis, sex, presurgical calcium and PTH levels, thymectomy, and histology were not significant prognostic factors for persistent disease. The Dutch MEN1 Registry found lower presurgical calcium levels in patients that required a second surgery during follow-up (10), but this finding has not been confirmed by others and can be related to the concept that more severe forms of PHPT have higher surgical success.

We investigated if different genotypes could help to predict surgical outcomes. Previous studies did not find genotype-phenotype correlation in relation to clinical presentation or severity $(8,24,25)$, but one study including 73 patients with MEN1 and surgically treated PHPT found a significantly lower risk of persistence and recurrence after <SPTX, but not after SPTX/TPTX, in patients with nonsense or frameshift mutations in exons 2,9 , and 10 when compared with patients with other mutations (10). Another study found that mutations in exon 3 were associated with worse recurrence rates; however, all patients with mutations in exon 3 had been initially operated with $<$ SPTX (11). Based on these previous reports we analyzed our data: early postsurgical results were significantly different depending on the mutated exon, with remission in all patients carrying mutations in exons 3, 6 and 7, but numbers in each category were small. We did not find a significantly different recurrencefree survival in patients harboring mutations in exons 2 , 9 and 10, nor in patients with mutations in exon 3 , nor in patients with mutations in exon 10 (the most frequently mutated exon in our series). Small numbers of patients in each group may have hindered the discovery of more significant associations. Our data, therefore, do not confirm previous findings in relation with a prognostic value of particular genotypes.

Long-term postsurgical hypoparathyroidism is not always irreversible in the case of MEN1 patients, since very small parathyroid remnants can grow and be able to secrete normal or excessive amounts of PTH. Among our ten patients with permanent hypoparathyroidism two required a second parathyroid surgery ( 28 and 124 months after the first one) and only two required treatment for hypoparathyroidism at their last follow-up visit.

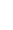

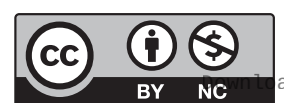


Other groups have outlined this phenomenon before $(10,11)$. Since overtreatment of hypoparathyroidism is not harmless (26), tapering calcium and vitamin D supplements can be required in some patients even many years after surgery.

Our study had several limitations. As a registry-based study, it was retrospective and spanned many years: current guidelines were not followed in some patients, because they were diagnosed and treated before these guidelines were written. Despite the active collaboration of many of the MEN group members in the collection of missing data, some relevant information was lacking due to variability in clinical practice, incomplete follow-up, or medical assistance in different hospitals throughout the patients' life. Therefore, postsurgical data of past surgeries were not available for some patients and, for others, we could not obtain confident information about the longterm development of bone and renal complications. Data were obtained in different settings and registered by several doctors, which may lead to variability in laboratory parameters and different criteria when interpreting the guidelines given by the Registry web.

In spite of these limitations, our work allows a critical appraisal of current clinical practice in our country: bone density is often overlooked, and when densitometry is ordered Z scores are not routinely registered, probably because clinicians are more familiar with $\mathrm{T}$ scores, less useful in these young patients. We are probably missing patients with osteoporosis, who could benefit from surgery $(14,27)$. On the other side, localization studies before the first surgery are overused.

In conclusion, our results confirm that PHPT is usually diagnosed in patients with MEN1 syndrome at a young age, and leads to relevant bone and renal complications. We can also support that SPTX and TPTX are the procedures of choice for PHPT in MEN1. However, almost half of the operated patients recurred in the long term. Longitudinal and randomized studies are needed to establish the best timing for surgery in order to minimize the development of chronic bone and renal complications as well as the need for reintervention. Recovery from hypoparathyroidism years after surgery is not unusual in these patients. Even if we had detailed information about individual mutations, we cannot confirm previous findings that supported a prognostic value of specific mutated exons of the MEN1 gene.

\section{Declaration of interest}

The authors declare that there is no conflict of interest that could be perceived as prejudicing the impartiality of the research reported.

\section{Funding}

The Spanish Registry of Multiple Endocrine Neoplasia, Pheochromocytmas and Paragangliomas is supported by IPSEN Pharmaceutical. This work did not receive any other specific grant from any funding agency in the public, commercial or not-for-profit sector.

\section{References}

1 Piecha G, Chudek J \& Wiecek A. Primary hyperparathyroidism in patients with multiple endocrine neoplasia type 1. International Journal of Endocrinology 20102010 928383. (https://doi. org/10.1155/2010/928383)

2 Thakker RV, Newey PJ, Walls GV, Bilezikian J, Dralle H, Ebeling PR, Melmed S, Sakurai A, Tonelli F, Brandi ML, et al. Clinical practice guidelines for multiple endocrine neoplasia type 1 (MEN1). Journal of Clinical Endocrinology \& Metabolism 201297 2990-3011. (https://doi. org/10.1210/jc.2012-1230)

3 Schreinemakers JM, Pieterman CR, Scholten A, Vriens MR, Valk GD \& Borel Rinkes IHM. The optimal surgical treatment for primary hyperparathyroidism in MEN1 patients: a systematic review. World Journal of Surgery 201135 1993-2005. (https://doi.org/10.1007/ s00268-011-1068-9)

4 Udelsman R, Akerstrom G, Biagini C, Duh QY, Miccoli P, Niederle B $\&$ Tonelli F. The surgical management of asymptomatic primary hyperparathyroidism: Proceedings of the Fourth International Workshop. Journal of Clinical Endocrinology \& Metabolism 201499 3595-3606. (https://doi.org/10.1210/jc.2014-2000)

5 Iacobone M, Carnaille B, Palazzo FF \& Vriens M. Hereditary hyperparathyroidism-a consensus report of the European Society of Endocrine Surgeons (ESES). Langenbeck's Archives of Surgery 2015400 867-886. (https://doi.org/10.1007/s00423-015-1342-7)

6 World Health Organization. Assessment of fracture risk and its application to screening for postmenopausal osteoporosis. Report of a WHO Study Group. Geneva, Switzerland: World Health Organization, 1994. (available at: https://apps.who.int/iris/ handle/10665/39142)

7 Goudet P, Cougard P, Verges B, Murat A, Carnaille B, Calender A Faivre J \& Proye C. Hyperparathyroidism in multiple endocrine neoplasia type I: surgical trends and results of a 256-patient series from groupe d'Etude des neoplasies endocriniennes multiples study group. World Journal of Surgery 200125 886-890. (https://doi. org/10.1007/s00268-001-0046-z)

8 Waldmann J, López CL, Langer P, Rothmund M \& Bartsch DK. Surgery for multiple endocrine neoplasia type 1-associated primary hyperparathyroidism. British Journal of Surgery 201097 1528-1534. (https://doi.org/10.1002/bjs.7154)

9 Lourenco DM, Jr, Coutinho FL, Toledo RA, Gonçalves TD, Montenegro FL \& Toledo SP. Biochemical, bone and renal patterns in hyperparathyroidism associated with multiple endocrine neoplasia type 1. Clinics 201267 (Supplement 1) 99-108. (https://doi. org/10.6061/clinics/2012(sup01)17)

10 Pieterman CR, van Hulsteijn LT, den Heijer M, van der Luijt RB, Bonenkamp JJ, Hermus AR, Borel Rinkes IH, Vriens MR, Valk GD \& DutchMEN1 Study Group. Primary hyperparathyroidism in MEN1 patients. A cohort study with longterm follow-up on preferred surgical procedure and the relation with genotype. Annals of Surgery 2012255 1171-1178. (https://doi.org/10.1097/ SLA.0b013e31824c5145)

11 Fyrsten E, Norlén O, Hessman O, Stalberg P \& Hellman P. Longterm surveillance of treated hyperparathyroidism for multiple endocrine neoplasia type 1: recurrence or hypoparathyroidism? World Journal of Surgery 201640 615-621. (https://doi.org/10.1007/ s00268-015-3297-9) 
12 Giusti F, Cianferotti L, Boaretto F, Cetani F, Cioppi F, Colao A, Davì MV, Faggiano A, Fanciulli G, Ferolla P, et al. Multiple endocrine neoplasia syndrome type 1: institution, management, and data analysis of a nationwide multicenter patient database. Endocrine 2017 58 349-359. (https://doi.org/10.1007/s12020-017-1234-4)

13 Eller-Vainicher C, Chiodini I, Battista C, Viti R, Mascia ML, Massironi S, Peracchi M, D'Agruma L, Minisola S, Corbetta S, et al. Sporadic and MEN1-related primary hyperparathyroidism: differences in clinical expression and severity. Journal of Bone and Mineral Research 200924 1404-1410. (https://doi.org/10.1359/jbmr.090304)

14 Lourenco DM, Jr, Coutinho FL, Toledo RA, Montenegro FL, CorreiaDeur JE \& Toledo SP. Early-onset, progressive, frequent, extensive, and severe bone mineral and renal complications in multiple endocrine neoplasia type 1-associated primary hyperparathyroidism. Journal of Bone and Mineral Research 201025 2382-2391. (https://doi. org/10.1002/jbmr.125)

15 Burgess JR, David R, Greenaway TM, Parameswaran V \& Shepherd JJ. Osteoporosis in multiple endocrine neoplasia type 1: severity, clinical significance, relationship to primary hyperparathyroidism, and response to parathyroidectomy. Archives of Surgery 1999134 1119-1123. (https://doi.org/10.1001/archsurg.134.10.1119)

16 Norton JA, Venzon DJ, Berna MJ, Alexander HR, Fraker DL, Libutti SK, Marx SJ, Gibril F \& Jensen RT. Prospective study of surgery for primary hyperparathyroidism (HPT) in multiple endocrine neoplasia-type 1 and Zollinger-Ellison syndrome: long-term outcome of a more virulent form of HPT. Annals of Surgery $20082 \mathbf{2 4}$ 501-510. (https://doi.org/10.1097/SLA.0b013e31815efda5)

17 Kann PH, Bartsch D, Langer P, Waldmann J, Hadji P, Pfützner A \& Klüsener J. Peripheral bone mineral density in correlation to diseaserelated predisposing conditions in patients with multiple endocrine neoplasia type 1. Journal of Endocrinological Investigation 201235 573-579. (https://doi.org/10.3275/7880)

18 Giusti F, Tonelli F \& Brandi ML. Primary hyperparathyroidism in multiple endocrine neoplasia type 1: when to perform surgery? Clinics 201267 (Supplement 1) 141-144. (https://doi.org/10.6061/ clinics/2012(sup01)23)

19 Nilubol N, Weinstein LS, Simonds WF, Jensen RT, Marx SJ \& Kebebew E. Limited parathyroidectomy in multiple endocrine neoplasia type 1-associated primary hyperparathyroidism: a setup for failure. Annals of Surgical Oncology 201623 416-423. (https://doi. org/10.1245/s10434-015-4865-9)
20 Dotzenrath C, Cupisti K, Goretzki PE, Yang Q, Simon D, Ohmann C \& Röher HD. Long-term biochemical results after operative treatment of primary hyperparathyroidism associated with multiple endocrine neoplasia types I and IIa: is a more or less extended operation essential? European Journal of Surgery 2001167 173-178. (https://doi. org/10.1080/110241501750099294)

21 Arnalsteen LC, Alesina PF, Quiereux JL, Farrel SG, Patton FN, Carnaille BM, Cardot-Bauters CM, Wemeau JL \& Proye CA. Long-term results of less than total parathyroidectomy for hyperparathyroidism in multiple endocrine neoplasia type 1. Surgery 2002132 1119-24; discussion 1124. (https://doi.org/10.1067/ msy.2002.128607)

22 Versnick M, Popadich A, Sidhu S, Sywak M, Robinson B \& Delbridge L. Minimally invasive parathyroidectomy provides a conservative surgical option for multiple endocrine neoplasia type 1-primary hyperparathyroidism. Surgery $2013 \mathbf{1 5 4} 101-105$. (https:// doi.org/10.1016/j.surg.2013.03.004)

23 Kluijfhout WP, Beninato T, Drake FT, Vriens MR, Gosnell J, Shen WT, Suh I, Liu C \& Duh QY. Unilateral clearance for primary hyperparathyroidism in selected patients with multiple endocrine neoplasia Type 1. World Journal of Surgery 201640 2964-2969. (https://doi.org/10.1007/s00268-016-3624-9)

24 Langer P, Wild A, Schilling T, Nies C, Rothmund M \& Bartsch DK. Multiple endocrine neoplasia type 1 . Surgical therapy of primary hyperparathyroidism. Chirurg 200475 900-906. (https://doi. org/10.1007/s00104-004-0838-4)

25 Marini F, Giusti F \& Brandi ML. Multiple endocrine neoplasia type 1: extensive analysis of a large database of Florentine patients. Orphanet Journal of Rare Diseases 201813 205. (https://doi.org/10.1186/ s13023-018-0938-8)

26 Bollerslev J, Rejnmark L, Marcocci C , Shoback DM, Sitges-Serra A, van Biesen W, Dekkers OM \& European Society of Endocrinology. European Society of Endocrinology Clinical Guideline: treatment of chronic hypoparathyroidism in adults. European Journal of Endocrinology 2015 173 G1-G20. (https://doi.org/10.1530/EJE-15-0628)

27 Coutinho FL, Lourenco DM, Jr, Toledo RA, Montenegro FL, CorreiaDeur JE \& Toledo SP. Bone mineral density analysis in patients with primary hyperparathyroidism associated with multiple endocrine neoplasia type 1 after total parathyroidectomy. Clinical Endocrinology 201072 462-468. (https://doi.org/10.1111/j.13652265.2009.03672.x)

Received in final form 15 September 2019 Accepted 23 September 2019

Accepted Preprint published online 24 September 2019
This work is licensed under a Creative Commons Attribution-NonCommercial 4.0 International License. ded from Bioscientifica.com at 04/26/2023 10:10:24AM 